\title{
CURADORIA DIGITAL E PRESERVAÇÃO DIGITAL: CRUZAMENTOS CONCEITUAIS
}

\author{
CURATION DIGITAL AND DIGITAL PRESERVATION: \\ CONCEPTUAL INTERSECTIONS \\ CURADURÍA DIGITAL Y PREVERVASIÓN DIGITAL: \\ CRUCES CONCEPTUALES
}

Thayse Natália Cantanhede Santos ${ }^{1}$

\begin{abstract}
RESUMO
A curadoria digital e a preservação digital têm como objeto de interesse a manutenção da informação digital ao longo do tempo. Tem na literatura científica definições próximas, contudo, a curadoria se apresenta como evolução natural dos processos de preservação de recursos digitais. A preservação digital pode ser vista como método, processo e modelo. Desse modo, foi constatado que existem pontos de interseção e de diferenciação que elucidam e indicam por que um conceito apareceu depois do outro e como cada um se apresenta em face à importância dada à gestão de grandes volumes de dados, especialmente os dados científicos. Após a comparação dos dois conceitos foi possível concluir que há mais unidade no entendimento do que é curadoria digital do que os conceitos de preservação e que as áreas de atuação de ambas complementam a gestão da informação digital como um todo.
\end{abstract}

PALAVRAS-CHAVE: Curadoria digital. Preservação digital. Gestão da Informação Digital.

\begin{abstract}
The digital curation and digital preservation have as object of interest the maintenance of digital information over time. In the scientific literature, they have close definitions, however, digital curation is presented as a natural evolution of the preservation of digital resources management processes. Digital preservation can be understood as a method, process and model. Thus, it was found that there are points of intersection and differentiation elucidating and indicating why a concept appeared after the other and how each is presented in face of the importance given to the management of large volumes of data, especially scientific data. After comparing the two concepts it was possible to conclude that there is more unity in the understanding of what curation is than there is in the preservation concepts. As a result, it is concluded that both concepts have fields of action that complement the management of digital information as a whole.
\end{abstract}

KEYWORDS: Digital Curation. Digital Preservation. Digital Information Management

\section{RESUMEN}

La curaduría y la preservación digital poseen el mismo objeto de interés: el mantenimiento de la información digital a través del tiempo. En la literatura científica, encontramos definiciones cercanas de los dos, sin embargo, curaduría se presenta como una evolución natural de la preservación de los procesos de recursos digitales. La preservación digital puede ser entendida como método, proceso y modelo. Por lo tanto, se encontró que existen puntos de intersección y diferenciación que elucidan por qué un concepto apareció después del otro y cómo cada uno se presenta a la vista de la importancia de la gestión de grandes volúmenes de datos, especialmente de datos científicos. Después de comparar los dos conceptos, se constata que hay más unidad en los conceptos de curación que en los conceptos de preservación encontrados. Como resultado, se concluye que

\footnotetext{
${ }^{1}$ Mestra em Ciência da Informação (UnB). Bibliotecária da Biblioteca Central (UnB). Brasília, DF. E-mail: thaysesantos@bce.unb.br. ORCID: http://orcid.org/0000-0003-1052-9197.

Submetido em: 03/08/2016 - Aceito em: 19/08/2016.
} 
ambos conceptos disponen de campos de acción que complementan la gestión de la información digital como un todo.

PAlABRAS Clave: Curaduría Digital. Preservación Digital. Gestión de la Información Digital.

\section{INTRODUÇÃO}

A informação digital, nos dias atuais, serve como testemunho da memória social, cientifica e cultural, representante do zeitgeist e direcionares dos caminhos possíveis da experiência humana no advento da sociedade coletivamente construída.

Recursos de informação digital são frágeis de modo distinto aos dos recursos analógicos, em grande medida por que são dinâmicos e complexos. Suas particularidades, volume e variedade, todavia, promoveram a discussão o que deve ser preservado, quando deve ser preservado e como deve ser preservado demanda processos muito mais ativos do que os exigidos para as fontes de analógicas.

A hercúlea tarefa de manter o que foi criado ou transformado para o meio digital de modo que caracterize o seu contexto, o seu propósito e funcionalidades originais conduziram a discussão em torno do que se designaria 'preservação digital. O termo 'preservação digital' foi inicialmente cunhado em 1990, em um projeto de pesquisa conjunto da biblioteca da Universidade de Cornell com a Xerox para designar a "utilização de tecnologias digitais para reformatar mídias analógicas, como parte do processo de preservação dessas mídias" (HIRTLE, 2010). Segundo Márdero Arellano (2008, p. 30) apenas a partir de 1996 a preservação digital passou a ser chamada como tal.

A incerteza do meio, evolução dos formatos, suportes tecnológicos para acesso, a corruptibilidade dos dados ao longo do tempo e o consequente risco de perda permanente dos dados são variáveis inerentes ao meio digital. As particularidades da informação em meio eletrônico - especialmente após o advento da Internet, do boom de informação ali disponibilizada, a variedade e complexidade dos objetos digitais criados - centralizam o papel da preservação digital. Nas palavras de Trevor Owens "assegurar acesso a longo prazo e usabilidade de objetos digitais complexos é de crítica importância para o future de quase todas as áreas das artes, cultura, humanidades e das ciências " (2015, p. 222).

A importância da preservação digital como ação primordial para manutenção da ciência, cultura e do conhecimento humano repete em parte o debate da preservação da informação registrada em suportes mais estáveis que o eletrônico. Contudo, o volume dos dados e rapidez com que são produzidos trazem à tona mais dilemas para as chamadas instituições de memória. Como tutoras, dotadas da responsabilidade de manter acessível a informação que comportam, enfrentam diretamente os desafios relacionados à avaliação da qualidade dos documentos eletrônicos e dos conteúdos de mídias, uma vez que cabe a elas estimar se os documentos são suficientemente bons para garantir sua acessibilidade e a usabilidade em longo prazo. 
A informação digital produzida intencionalmente (ou não) gera uma série de dados, através de visualizações, cliques, compras, buscas e todo o comportamento do usuário que está sendo gravando para posterior uso (EINAV; LEVIN, 2014). Esse volume gigantesco de dados relacionáveis ou Big Data acrescentam ainda mais pressão à questão da preservação da informação para uso futuro, Segundo Vieira et al. (2012), a Big Data se caracteriza por: 1. Dados na ordem de dezenas ou centenas de Terabytes; 2. Poder de crescimento elástico horizontal; 3. Fácil distribuição de dados; 4. Tipos variados de dados.

A pretensão do trabalho é analisar como as definições de preservação e de curadoria digital convergem por meio do cruzamento dos conceitos. Partiremos do entendimento gradual da preservação como modelo, processo, método e da adoção do termo 'curadoria' como evolução natural aos esforços necessários ao tratamento da informação digital em fase à novos desafios com a gestão para manutenção de grandes conjuntos de dados científicos.

\section{METODOLOGIA}

Para esta investigação qualitativa, buscamos pensar este estudo sobre a evolução do conceito de preservação e no segundo momento abordar o conceito de curadoria dados científicos para construção de quadro comparativo entre as duas áreas de estudo e contribuir para o entendimento mais amplo dos dois conceitos, compreendidos dentro do conjunto coletivo de esforços para manutenção da informação digital ao longo do tempo.

O presente estudo estrutura-se da seguinte forma: após a introdução, disserta-se sobre a preservação sob diferentes aspectos e então o conceito de curadoria digital é apresentado. $\mathrm{Na}$ seção 5, faremos um cruzamento dos conceitos a fim de encontrar pontos comuns e diferenciadores de ambos os conceitos, na tentativa de compreendê-los mais profundamente e contribuir para a discussão atual sobre a manutenção da preservação digital ao longo de grandes períodos.

\section{PREServaÇÃo digital COMo método, PROCESSO E MOdelo}

Neil Beagrie, em publicação de 2008, relata que "uma das maiores dificuldades de qualquer disciplina emergente, como a preservação digital, é a falta de taxonomia definitiva de termos" (p. 24). Isso ocorre, pois o mesmo termo é usado de maneiras diferentes por diferentes comunidades. O mesmo acontece com as definições de termos chave como a preservação digital. Uma vez que objeto de interesse das partes envolvidas com a manutenção da informação digital ao longo do tempo se diferencia de acordo com os seus interesses e objetivos.

Isso é facilmente constatado quando confrontamos as diferentes acepções de preservação digital encontradas na literatura. Tal fenômeno explica por que ora ela pode ser encarada como método, processo ou modelos. As visões e interesses diversos tornam difícil 
definir o termo inequivocamente.

De início, os primeiros esforços de preservação partiram da necessidade de achar soluções de coleções digitais especialmente no contexto das bibliotecas, que passaram a lidar com informação digital e a questionar como tornariam essas coleções acessíveis por meio da digitalização dos documentos.

\subsection{Preservação pelo seu propósito, finalidade ou objeto de interesse}

Conway inaugura a discussão, definindo a preservação a partir de sua finalidade: “o propósito da preservação é de proteger informação de valor permanente para o acesso de gerações presentes e futuras" (CONWAY, 1990). Quatro anos depois é publicado o Report of the Task Force on Archiving of Digital Information considerado um marco teórico sobre os requisitos é necessários para preservação a longo prazo. Ele previa um sistema nacional de arquivos digitais que teria várias funções e seria "coletivamente responsável pela acessibilidade a longo prazo da herança social, econômica, cultural e intelectual na forma digital da nação" assim como um sistema de auditoria e certificação de repositórios. Há também discussão extensiva referente a construção de uma ciberinfraestrutura nacional para tal empreendimento e envolveu indivíduos de várias instituições (SANTOS, 2014). Apesar de ser pedra angular da área, o documento abarca o assunto sem apresentar uma definição clara do termo, a integridade, complexidade, conteúdo, proveniência e contexto dos objetos digitais e a estrutura institucional necessária para torná-las acessíveis são os itens destacados.

\subsection{Preservação como processo ou método}

A preservação é comumente definida como uma séria de processos ou tarefas que se executadas garantiriam a permanência da informação ao longo do tempo. Há alguma flutuação em torno do que seriam esses processos. Assim, a "preservação digital é o método de manter materiais digitais vivos para que permaneçam utilizáveis como avanços tecnológicos tornam hardwares originais e especificações de softwares obsoletos" (PRYTHERCH, 2005) e ou a preservação digital está emergindo como um processo confiável, ainda há muito debate em curso, e ceticismo abunda, a respeito da viabilidade e até mesmo o significado desse processo. Dada a natureza das tecnologias de armazenamento eletrônicos e a natureza efêmera de páginas Web, muitos duvidam que a preservação digital vai se tornar uma realidade (JANTZ; GIARLO, 2005).

A definição do Preservation Handbook também interpreta que a preservação digital é uma série de atividades para assegurar acesso contínuo de materiais digitais enquanto for necessário. Por último, a preservação digital abrange uma ampla gama de atividades destinadas a estender a vida útil de arquivos de computador legíveis por máquina e protegêlos de falha de mídia, perda física e obsolescência (UNIVERSITY OF MINNESOTA LIBRARIES, 2016). 
A preservação também é considerada em 'níveis', como é o caso da definição de 2013 da National Digital Stewardship Alliance (NDSA), um consórcio de organizações comprometidas com a preservação a longo prazo da informação digital. Os níveis de preservação digital são um conjunto hierárquico de recomendações para como as organizações devem começar a construir ou melhorar as suas atividades de preservação digital.

Tabela 1. Versão 1 de níveis de preservação digital

\begin{tabular}{|c|c|c|c|c|}
\hline & $\begin{array}{l}\text { Level } 1 \text { (Protect } \\
\text { your data) }\end{array}$ & $\begin{array}{l}\text { Level } 2 \text { (Know your } \\
\text { data) }\end{array}$ & $\begin{array}{l}\text { Level } 3 \text { (Monitor your } \\
\text { data) }\end{array}$ & $\begin{array}{l}\text { Level } 4 \text { (Repair your } \\
\text { data) }\end{array}$ \\
\hline $\begin{array}{l}\text { Storage and } \\
\text { Geographic } \\
\text { Location }\end{array}$ & $\begin{array}{l}\text { - Two complete } \\
\text { copies that are not } \\
\text { collocated } \\
\text { - For data on } \\
\text { heterogeneous } \\
\text { media (optical } \\
\text { discs, hard drives, } \\
\text { etc.) get the content } \\
\text { off the medium and } \\
\text { into your storage } \\
\text { system }\end{array}$ & $\begin{array}{l}\text {-At least three } \\
\text { complete copies } \\
\text { - At least one copy in a } \\
\text { different geographic } \\
\text { location } \\
\text { - Document your } \\
\text { storage system(s) and } \\
\text { storage media and } \\
\text { What you need to use } \\
\text { them }\end{array}$ & $\begin{array}{l}\text {-At least one copy in a } \\
\text { geographic location } \\
\text { with a different } \\
\text { disaster threat } \\
\text { - Obsolescence } \\
\text { monitoring process for } \\
\text { your storage system(s) } \\
\text { and media }\end{array}$ & $\begin{array}{l}\text { - At least three copies } \\
\text { in geographic } \\
\text { locations with different } \\
\text { disaster threats } \\
\text { - Have a } \\
\text { comprehensive plan in } \\
\text { place that will keep } \\
\text { files and metadata on } \\
\text { currently accessible } \\
\text { media or systems }\end{array}$ \\
\hline $\begin{array}{l}\text { File Fixity and Data } \\
\text { Integrity }\end{array}$ & $\begin{array}{l}\text { - Check file fixity on } \\
\text { ingest if it has been } \\
\text { provided with the } \\
\text { content } \\
\text { - Create fixity info if } \\
\text { it wasn't provided } \\
\text { with the content }\end{array}$ & $\begin{array}{l}\text { - Check fixity on all } \\
\text { ingests } \\
\text { - Use write-blockers } \\
\text { When working with } \\
\text { original media } \\
\text { - Virus-check high risk } \\
\text { content }\end{array}$ & $\begin{array}{l}\text { - Check fixity of } \\
\text { content at fixed } \\
\text { intervals } \\
\text { - Maintain logs of fixity } \\
\text { info; supply audit on } \\
\text { demand } \\
\text { - Ability to detect } \\
\text { corrupt data } \\
\text { - Virus-check all } \\
\text { content }\end{array}$ & $\begin{array}{l}\text { - Check fixity of all } \\
\text { content in response to } \\
\text { specific events or } \\
\text { activities } \\
\text { - Ability to } \\
\text { replace/repair } \\
\text { corrupted data } \\
\text { - Ensure no one } \\
\text { person has write } \\
\text { access to all copies }\end{array}$ \\
\hline Information Security & $\begin{array}{l}\text { - Identify who has } \\
\text { read, write, move } \\
\text { and delete } \\
\text { authorization to } \\
\text { individual files } \\
\text { - Restrict who has } \\
\text { those authorizations } \\
\text { to individual files }\end{array}$ & $\begin{array}{l}\text { - Document access } \\
\text { restrictions for content }\end{array}$ & $\begin{array}{l}\text { - Maintain logs of who } \\
\text { performed what } \\
\text { actions on files, } \\
\text { including deletions } \\
\text { and preservation } \\
\text { actions }\end{array}$ & - Perform audit of logs \\
\hline Metadata & $\begin{array}{l}\text { - Inventory of } \\
\text { content and its } \\
\text { storage location } \\
\text { - Ensure backup } \\
\text { and non-collocation } \\
\text { of inventory }\end{array}$ & $\begin{array}{l}\text { - Store administrative } \\
\text { metadata } \\
\text { - Store transformative } \\
\text { metadata and log } \\
\text { events }\end{array}$ & $\begin{array}{l}\text { - Store standard } \\
\text { technical and } \\
\text { descriptive metadata }\end{array}$ & $\begin{array}{l}\text { - Store standard } \\
\text { preservation metadata }\end{array}$ \\
\hline File Formats & $\begin{array}{l}\text { - When you can } \\
\text { give input into the } \\
\text { creation of digital } \\
\text { files encourage use } \\
\text { of a limited set of } \\
\text { known open } \\
\text { formats and codecs }\end{array}$ & $\begin{array}{l}\text { - Inventory of file } \\
\text { formats in use }\end{array}$ & $\begin{array}{l}\text { - Monitor file format } \\
\text { obsolescence issues }\end{array}$ & $\begin{array}{l}\text { - Perform format } \\
\text { migrations, emulation } \\
\text { and similar activities } \\
\text { as needed }\end{array}$ \\
\hline
\end{tabular}

Fonte: NDSA Levels of Digital Preservation, 2013.

O tratamento da informação em níveis é uma evolução interessante, pois aproxima as 
políticas e práticas para a gestão da informação digital de um modelo global de tratamento da informação digital para acesso futuro. A busca de um modelo de representação da informação que contemple desde a sua criação, avaliação, transformação e acesso aponta que o interesse da preservação da informação em meio digital vai além da criação e uso de sistemas que atendam aspectos pontuais de preservação. Nessa direção,

\begin{abstract}
ainda que muitas ferramentas de softwares existam para executar tarefas de preservação, sua condição de suporte, qualidade, confiabilidade etc., não estão sob controle do proprietário dos conteúdos e são muito incertos e incomprovados para serem totalmente confiáveis e implementados em fluxos de trabalho de preservação (FRESA et al, C., 2015, p. 192)
\end{abstract}

A visão nivelada da preservação digital é a mais próxima da abordagem preservacionista que considera ações em todas as etapas do ciclo de vida dos documentos.

\title{
3.3 Preservação digital ao longo do ciclo de vida dos objetos
}

A preservação digital também pode ser interpretada como a administração do ciclo de vida de um documento digital, compreendendo as atividades de armazenamento da informação em suportes digitais, a manutenção das coleções, o acesso permanente e a difusão de documentos digitais. Há consenso que tal empreendimento, por sua dimensão e complexidade deve ser compartilhada entre todos os atores envolvidos diretamente na criação e administração de informação, além do desenvolvimento de ações de cooperação nacional e internacional. Nesse sentido, Márdero Arellano (2004, p.16) alguns princípios que devem ser observados como:

a) armazenar em ambiente estável e controlável;

b) elaborar estratégias para preservação no momento em que os recursos digitais são criados;

c) garantir a permanência e integridade da fonte, a partir de uma política institucional que leve em consideração aspectos legais e culturais como licenças e permissões de copyright;

d) implementar procedimentos apropriados de manuseio;

e) transferir para uma mídia de armazenamento padrão.

Resumidamente, os conceitos e ações necessárias a preservação evoluíram de modo a acompanhar acrescente complexidade dos objetos digitais, de maneira a sustentar suas características intrínsecas e o seu contexto de criação e uso futuro como visto na Fig. 1. 


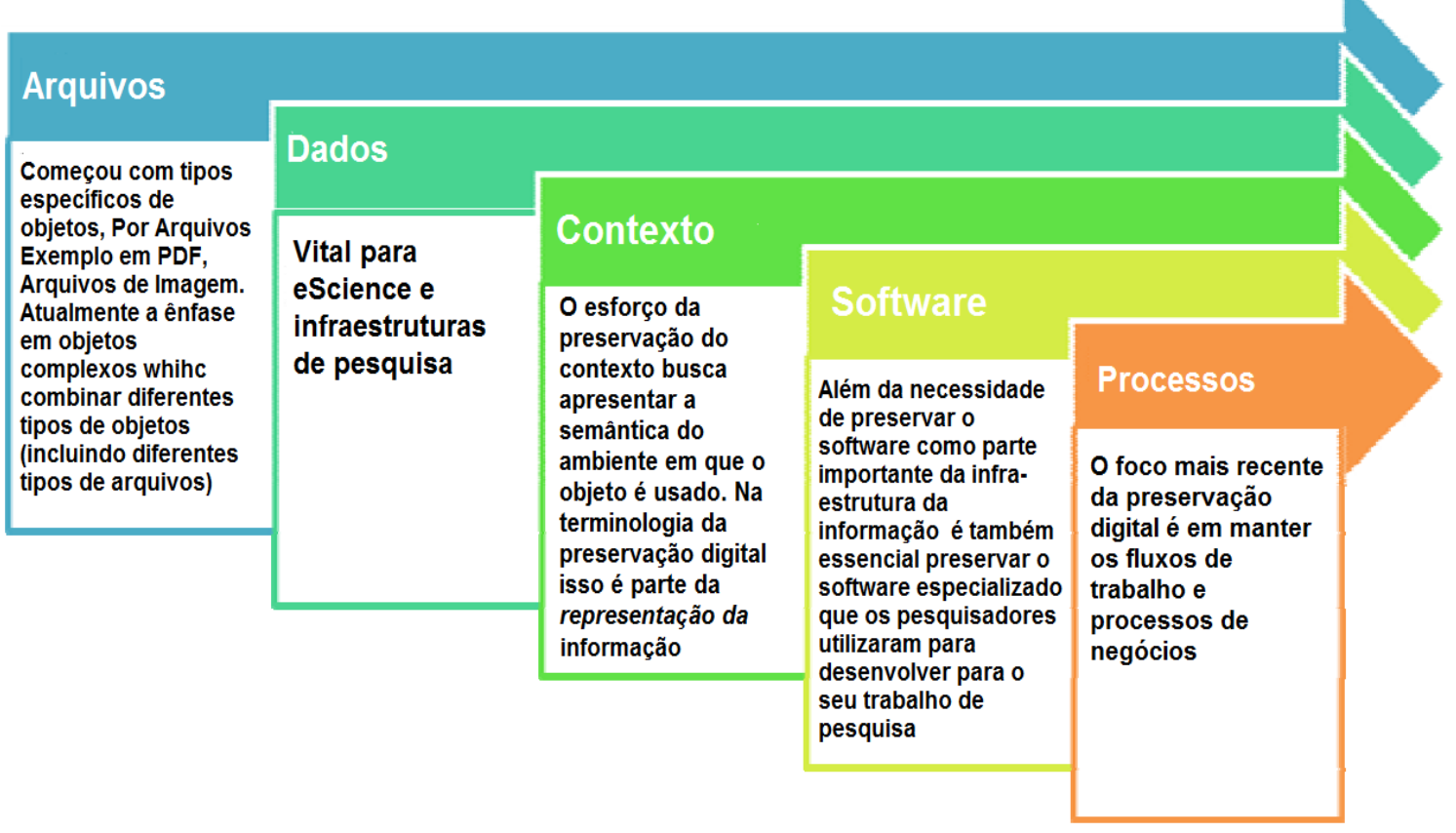

Figura 1. Evolução de objetos digitais abordadas pela preservação digital Fonte: RUUSALEPP; DOBREVA (2013, p. 8). Tradução da autora.

As definições iniciais entendem a preservação digital como um esforço formal para garantir que as informações digitais de valor permanente continuem a ser acessíveis e utilizáveis. Essas acepções são demasiado genéricas e apenas circunscrevem os limites da área. Também não cabe entender a preservação como uma sequiência contínua de fatos ou operações que se executados com certa unidade garantem os objetivos das organizações de manutenção informação digital. A preservação digital exige entendimento da complexidade que tal empreitada compreende.

\section{CURADORIA DIGITAL}

O termo curadoria pode ser definido como o "ato ou efeito de curar, função, atributo, cargo, poder de curador, curatela” (HOUAISS; VILLAR, p. 892, 2007). Contudo, o termo 'curadoria' foi transposto de museus e bibliotecas às mídias interativas (a Web e seus novos canais de comunicação). A criação de dados científicos de modo distribuído e o fenômeno da Big Data (dados estruturados e não estruturados criados em massa) e a evolução complexa dos objetos digitais forjaram o cenário favorável ao que seria chamado de início de 'curadoria de dados', também denominada em inglês de eScience. Nas palavras de Huwe (2013, p. 19)

o fato de estarmos nos movendo a toda velocidade para a era do crowdsourced, webcrawled e 'dados marcados' (web tagged) está criando novos caminhos para a pesquisa científica, contudo ainda existe valor em programas de aquisição de dados já em andamento. A emergência de praticas de pesquisa de Big Data, que esta revolucionando o modo como as pessoas analisam pacotes de informação pequenos ou grandes, pode realmente fortalecer o impacto das habilidades de descoberta das 


\begin{abstract}
bibliotecas. Como resultado, profissionais da informação se beneficiam não apenas por meio da curadoria digital e envolvendo-se na análise em Big Data, mas através da prática contínua do trabalho de referência e pela descoberta de recursos. A biblioteca, assim, está sendo promovida como 'laboratório de soluções' para curadoria de dados. O equilíbrio essencial pode ser encontrado quando lembramos que habilidades inerentes ao trabalho de referência - descoberta, reconhecimento de padrões e análise - oferecem meios poderosos para transmitir nossa proposta de valor, não apenas como curadores de dados, mas também como conselheiros da informação com habilidades avanças de aquisição de dados.
\end{abstract}

Os grandes volumes de dados, especialmente os científicos, demandam a criação de uma infraestrutura para sua curadoria, "entendendo o termo hiperomínico que designa as atividades e estratégias que compreendem a administração de uma parte" (SANTOS, 2014). Especificamente, a curadoria digital é definida com a seleção preservação, manutenção, coleção e arquivamento de ativos digitais.

A curadoria digital tomou impulso como área de pesquisa principalmente após a criação do Digital Curation Centre (DCC) em 2004. Sua implementação estava prevista no Continuing access and digital preservation strategy for JISC lançado em $2002^{2}$ pelo JISC (Joint Information Systems Comittee). Sua função seria "coordenar o desenvolvimento de novas pesquisas, serviços genéricos e ferramentas para a curadoria digital que apoiar a próxima fase dos elementos-chave daquela estratégia” (BEAGRIE, 2004, p.7).

Beagrie fala sobre a emergência do termo e também do conceito.

o termo 'curadoria digital' está sendo usado cada vez mais usado para as ações necessárias para manter dados de pesquisa em meio digital e outros materiais ao longo de seus ciclos de vida e do tempo para as gerações atuais e futuras de usuários. Implícita nesta definição estão os processos de arquivamento digital e preservação digital mas também inclui os processos necessários para criação de dados de qualidade e gestão, e a capacidade de acrescentar valor aos dados para produção de novas fontes de informação e conhecimento" (BEAGRIE, 2004, p. 7).

Segundo o DCC a curadoria envolve a manutenção, preservação e adição de valor aos dados de pesquisa digital de todo o seu ciclo de vida.

Rubridge et al. aponta que o "DCC vê a curadoria digital como um continuum de atividades, apoiando os requisitos tanto para uso corrente como futuro" (RUBRIDGE et al, 2005, p. 1). Pennock (2006) relaciona o conceito de curadoria com bibliotecas digitais, apresentando as dificuldades de se fazer curadoria em repositórios com informações de natureza e formatos diversos. Hedges, et al (2007) enfatizam algumas das limitações da preservação digital e apontam a curadoria como conjunto de ações que garantam a qualidade, integridade e auditoria de conjuntos complexos de informação a partir de ações executadas durante o ciclo de vida dos objetos digitais.

2 Continuing access and digital preservation strategy for JISC. Disponível em: http://www.jisc.uk/media/documents/publications/strategypreservation.pdf. Acesso em: 10 de setembro de 2016) 
Uribe-Martínez e McDonald (2008, p. 276) argumentam que "todas as atividades de gestão de dados científicos se resumem ao termo curadoria de dados" e consideram a definição a definição do DCC de curadoria digital, o que indica que os termos curadoria de dados e curadoria digital são entendidos como intercambiáveis, não cabendo diferenciação na sua definição. Inge Angevaare (ANGEVAARE, 2009, p. 2) afirma que "dados digitais requerem cuidado específico, a assim chamada 'curadoria', que inclui "preservação", para resistir ao teste do tempo".

Para Lee e Tibbo (2011, p. 124) a curadoria, termo que passou a ser usado recentemente, congrega correntes díspares de atividade que têm cada vez mais reconhecido que compartilham um conjunto comum de desafios e oportunidades e além de refletir a crescente confluência de comunidades antes distintas. Ray (2012, p. 607) examina como os termos curadoria digital e ciberinfraestrutura se relacionam e descrevem os conceitos associados como dados que devem ser geridos, preservados, manipulados e disponibilizados para uso a longo prazo. Para o autor a "curadoria digital demanda atenção às questões de preservação e interoperabilidade no início do ciclo de vida dos dados". Sayão e Sales (2012, p. 184) afirmam que a curadoria digital é resultado do acúmulo dos "conhecimentos e práticas em preservação e acesso a recursos digitais que resultaram num conjunto de estratégias, abordagens tecnológicas e atividades que agora são coletivamente conhecidas com 'curadoria digital'.

Weidner e Alemneh (2013) apresentam uma definição de curadoria semelhante à do DCC:

atividade contínua de gestão e melhoria do uso de recursos digitais durante os seus ciclos de vida ao longo do tempo. A curadoria digital começa quando o item é criado (nascido digital ${ }^{3}$ ) ou selecionado para digitalização (analógico) e continua por meio de processamento de imagem, captura de metadados, criação derivativa e preservação para acesso a longo prazo. (tradução nossa).

Todas as acepções se aproximam do que foi estabelecido de início pelo DCC como curadoria. Existe certa conformidade de que a curadoria é termo mais abrangente do que a preservação digital ao frisar a necessidade de tratamento dos documentos em todas as etapas do seu ciclo de vida. Yakel (2007) indica que a curadoria é um termo guarda-chuva que abarca preservação digital, curadoria de dados, gestão de registros eletrônicos e gerenciamento de ativos digitais. Apesar de pensar a gestão de objetos digitais de modo mais amplo e apontar a importância da intervenção planejada em todas as etapas dos seus ciclos de vida, a curadoria deve ser entendida como termo hiperônimo que ainda está em desenvolvimento.

\footnotetext{
${ }^{3}$ Também utiliza-se o termo nato ou nascido digital para se fazer referência aos documentos originalmente digitais.
} 


\title{
5 CRUZAMENTOS CONCEITUAIS
}

Na tentativa de abarcar a manutenção da informação digital considerando todos os seus aspectos e o grande volume de dados criados para o compartilhamento e uso futuro, seja como modelo, processo ou método, a preservação digital evoluiu de abordagens simplistas (que consideravam atividades separadas para tratamento das particularidades do documento digital) para abordagens holísticas. O Preservation Digital Reformatting Program ${ }^{4}$ da Library of Congress aponta que:

\begin{abstract}
porque o termo 'preservação digital 'pode ter vários significados, inclusive como contrastar como a preservação digital de dados e o uso de tecnologia digital para preservar os dados analógicos," gestão do ciclo de vida "é intencionalmente usado no Programa de Preservação Digital para reformatação especificamente refere-se às tecnologias de fluxo de trabalho e requisitos progressivos necessários para garantir a sustentabilidade a longo prazo e acesso a objetos e/ou metadados digitais (2014, sem paginação).
\end{abstract}

Desse modo, a criação de ciclos de vida da informação digital emergiu da necessidade de se gerir conteúdo, considerando a formulação e fluxos de trabalho para tipos específicos de proprietários de conteúdo. Neles, a informação em meio digital se move através de estágios, desde a sua criação até a preservação contínua, gestão e acesso ao longo do tempo.

A curadoria de dados surgiu com trata das atividades de gestão requeridas para manter dados de pesquisa a longo prazo de modo que esteja disponível para o reuso e para a preservação. Na ciência, curadoria de dados - também denominada em inglês de eScience pode indicar o processo de extração de informação importante de textos científicos como artigos de pesquisa por experts, que serão convertidos em formato eletrônico, como uma entrada de uma base de dados eletrônica. Em termos amplos, curadoria significa uma gama de atividades e processos feitos para criar, gerir, manter e validar um componente. $\mathrm{Na}$ tentativa de comparar ambos os conceitos, apresentamos o Quadro 1.

Quadro 1. Curadoria digital e Preservação Digital comparadas

\begin{tabular}{|c|c|c|}
\hline Objetivo & Curadoria digital & Preservação digital \\
\hline Abordagem & $\begin{array}{c}\text { Garantir a sustentabilidade dos } \\
\text { dados a longo prazo }\end{array}$ & $\begin{array}{c}\text { Garantir acesso a longo prazo da } \\
\text { informação armazenada digitalmente }\end{array}$ \\
\hline $\begin{array}{c}\text { Envolve a manutenção, } \\
\text { preservação e agregação de valor } \\
\text { aos dados da pesquisa digital em } \\
\text { toda sua vida útil }\end{array}$ & $\begin{array}{c}\text { Envolve a retenção do objeto } \\
\text { informacional e seu significado }\end{array}$ \\
\hline
\end{tabular}

\footnotetext{
${ }^{4}$ Preservation Digital Reformatting Program. URL:

http://www.loc.gov/preservation/about/prd/presdig/index.html
} 


\begin{tabular}{|c|c|c|}
\hline Atividades necessárias & $\begin{array}{c}\text { Seleção, preservação, manutenção, } \\
\text { coleta, arquivamento e reavaliação } \\
\text { de ativos digitais. }\end{array}$ & $\begin{array}{c}\text { Seleção, manutenção, coleta, } \\
\text { arquivamento e reavaliação de ativos } \\
\text { digitais. }\end{array}$ \\
\hline Técnicas & $\begin{array}{c}\text { Criação de políticas, atividades em } \\
\text { cada etapa do ciclo de vida dos } \\
\text { objetos ; considera a natureza de } \\
\text { cada objeto }\end{array}$ & $\begin{array}{c}\text { migração de dados e encapsulamento; } \\
\text { considera a natureza de cada objeto } \\
\text { Criac̃o de políticas, emulação, } \\
\text { Considerada atividade contínua }\end{array}$ \\
\hline Congevidade & Considerada atividade contínua \\
\hline
\end{tabular}

Fonte: autoria própria

A curadoria digital é um termo que abarca definições correlatas voltadas à seleção, enriquecimento, tratamento e preservação da informação para o acesso e uso futuro, seja ela de natureza científica, administrativa ou pessoal. Tanto a curadoria quanto a preservação consideram a natureza dos objetos digitais, a sua representação e a preocupação com acesso futuro desses ativos digitais. A curadoria digital é um termo amplo utilizado para designar as atividades necessárias à gestão da informação em meio digital maiores que a preservação, ela trata da manutenção consciente e orientada à preservação e acesso dos ativos digitais resultantes da pesquisa científica.

\section{RESULTADOS}

A investigação evidenciou que a curadoria digital é um conceito ou expressão que designa, contém ou descreve campo de atuação relacionados à gestão da informação digital para preservação a longo prazo e para acesso futuro. É possível constatar que existe mais proximidade entre as definições de curadoria encontradas do que as definições existentes do que seria preservação.

A preservação evoluiu de uma gama de conceitos e ainda hoje é encarada de várias maneiras, de modo mais restrito (atividades ou processos) ou amplo (definições gerais). Os diferentes pontos de interesse dão importância distinta quanto ao objetivo ou propósito da preservação e, portanto, definem a PD. A diversidade de representações do que seria preservação digital, ainda que enriqueça a discussão, acaba por criar alguma confusão no entendimento de quais seriam seus limites e práticas.

A construção de modelos que contemplem todas as fases do ciclo de vida surgiu como processo natural na tentativa de abarcar todas as variáveis que devem ser consideradas quando do tratamento da informação digital. Naturalmente, surgimento curadoria digital, termo ainda mais amplo que a preservação digital, indica que a preservação digital, ainda que abarcasse um amplo espectro de atividades não responderia sozinha aos novos e mais completos objetos digitais que vem sendo criados. 


\section{CONCLUSÕES}

A expressão curadoria digital foi sugerida no começo da década de 2000, pelo menos uma década depois da emergência da preservação como saída para a questão da manutenção da informação digital. A curadoria, contudo, surgiu com a Internet já consolidada como canal mundial para criação e disseminação da informação e a crescente percepção de que conjuntos massivos de dados construídos coletivamente devem ser preservados para uso corrente e futuro.

A preservação digital já havia imperava na comunidade científica como necessidade inerente ao meio eletrônico. A curadoria digital pode ser interpretada como evolução do entendimento das questões a preservação, não como panacéia, a não ser que esforços em todas as direções necessárias sejam feitos. Ela não veio para substituir a preservação e sim incorporar as melhores práticas criadas e contribuir para a preservação da memória cultural e científica que é construída de modo distribuído, massiva e não estruturada.

\section{REFERÊNCIAS}

ANGEVAARE, Inge. Taking Care of Digital Collections and Data: "Curation" and Organisational Choices for Research Libraries. Liber Quarterly: The Journal of European Research Libraries, v. 19, n. 1, 2009. Disponível em: < http://liber.library.uu.nl/index.php/lq/article/view/7948>. Acesso em: 21 jun. 2016.

ASSOCIATION FOR LIBRARY COLLECTIONS \& TECHNICAL SERVICES. Definitions of digital preservation: Prepared by the ALCTS Preservation and Reformatting Section, Working Group on Defining Digital Preservation. Washington: ALA, 2007. Disponível em: < http://www.ala.org/alcts/resources/preserv/defdigpres0408>. Acesso em: 25 maio 2016.

BEAGRIE, NEIL. Preservation management of digital materials: The Handbook. Digital Preservation Coalition, nov. 2008. Disponível em: < http://www.dpconline.org/component/docman/doc_download/299-digital-preservationhandbook $>$. Acesso em: 04 jul. 2016.

BEAGRIE, Charles. The digital curation centre. Learned Publishing, v. 17, n.1, jan. 2004, p.7-9.

COMMISSION ON PRESERVATION AND ACCESS AND THE RESEARCH LIBRARIES GROUP. Preserving Digital Information: Report of the Task Force on Archiving of Digital Information. Maio 1996. Disponível em: < http://www.clir.org/pubs/reports/pub63watersgarrett.pdf>. Acesso em: 07 maio 2016.

CONWAY, Paul. Digitizing Preservation. Library Journal, v. 119, n. 2, p. 42-45, fev. 1994.

CONWAY, Paul. Preservation in the Ditigal World. Washington, D.C.: Commission on Preservation and Access, 1996. 
CORNELL/XEROX/CPA JOINT STUDY IN DIGITAL PRESERVATION: Progress Report Number 2. The Electronic Library, v. 10 n. 3, p.155-163, 1992.

CURADORIA, In: HOUAISS, Antonio; VILLAR, Mauro de Salles. Dicionário Houaiss da Língua Portuguesa. Rio de Janeiro: Objetiva, 2007. p. 892.

EINAV, Liran; LEVIN, Jonathan D. The data revolution and economic analysis.

National Bureau of Economic Research, 2014. Disponível em:

<http://web.stanford.edu/ jdlevin/Papers/BigData.pdf>. Acesso em: 09 jul. 2016.

FRESA, Antonella; JUSTRELL, Börje; PRANDONI, Claudio. Digital curation and quality standards for memory institutions: PREFORMA research Project. Archival Science, v. 15, Issue 2, p. 191-216, jun. 2015.

HEDGES, Mark; HASAN, Adil; BLANKE, Tobias. Curation and preservation of research data in Irods data grid. E-SCIENCE 2007: Third IEEE International Conference on eScience and Gid Computing, Proceedings. IEEE, 2007, p. 457-464.

HEDSTROM, Margaret. Digital preservation: a time bomb for digital libraries. Computers and the Humanities, v. 31, p. 189-202, 1998. Disponível em:<http://deepblue.lib.umich.edu/bitstream/handle/2027.42/42573/10579_2004_Article_15 3071.pdf,jsessionid=5395F9215FE2F1173FBD31FE3C55361A? sequence=1>. Acesso em: 30 jun. 2016.

HIRTLE, Peter. The history and current state of digital preservation in the United States. In: Metadata and Digital Collections: A Festschrift in Honor of Thomas P. Turner. Ithaca, NY: Cornell University Library: 2010.

HUWE, Terence K. Data discovery and data curation going hand in hand. Computers in Libraries, v. 33, n. 3, abr. 2013, p. 17-19. Disponível em: < http://www.infotoday.com/cilmag/apr13/Huwe--Data-Discovery-and-Data-Curation-GoingHand-in-Hand.shtml>. Acesso em: 23 maio 2016.

JANTZ, Ronald; GIARLO, Michael J. Digital preservation: prchitecture and pechnology for prusted digital repositories. D-Lib, v. 11, n. 6, jun. 2005. Disponível em: <http://www.dlib.org/dlib/june05/jantz/06jantz.html>. Acesso em: 23 jul. 2016.

LEE, Christopher; TIBBO, Helen. Where's the Archivist in Digital Curation? Exploring the Possibilities through a Matrix of Knowledge and Skills. Archivaria, n.72, Fall 2011, p.12367.

MÁRDERO ARELLANO, Miguel. Preservação de documentos digitais. Ciência da Informação, v. 33, n.2, p.15-27, maio/ago. 2004. Disponível em: <https://core.ac.uk/download/files/418/11878016.pdf>. Acesso em: 31 jul. 2016.

MÁRDERO ARELLANO, Miguel A. Critérios para a preservação digital da informação científica. 2008. 356 f. Tese (Doutorado em Ciência da Informação) - Universidade de \begin{tabular}{l|l|l|l|l|l|l|}
\hline (C) Rev. Digit.Bibliotecon. Cienc. Inf. & Campinas, SP & v.14 & n.3 & p.450-464 & set/dez. 2016 & ISSN 1678-765X \\
\hline
\end{tabular} 
Brasília,

Brasília,

2008.

Disponível

em: <http://repositorio.bce.unb.br/bitstream/10482/1518/1/2008_MiguelAngelMarderoArella no.pdf>. Acesso em: 31 jul. 2016.

NATIONAL DIGITAL STEWARDSHIP ALLIANCE. The NDSA Levels of Digital Preservation: An Explanation and uses. In: Proceedings of the Archiving (IS\&T) Conference, April 2013, Washington, DC Disponível em: <http://ndsa.org/documents/NDSA_Levels_Archiving_2013.pdf>. Acesso em 31 jun. 2016.

NORA, Pierre. Entre memória e história: a problemática dos lugares. Revista Projeto História. São Paulo, v. 10, p.7-28, 1993.

OWENS, Trevor. Preserving complex objects. Janet Delve, David Anderson (Ed.). Facet Publishing, Greenwich, CT (2014), Journal of Academic Librarianship, v. 41, n. 2, p. 222, mar. 2015.

PENNOCK, Maureen. Digital curation and the management of digital library cultural heritage resources. Local Studies Librarian, v. 25, n. 2, p. 3-7, 2006. Disponível em: <www.ukoln.ac.uk/ukoln/staff/m.pennock/publications/docs/lsl-curation_mep.pdf >. Acesso em: 23 jul. 2016.

PRYTHERC, Ray. Harrod's Librarians' Glossary and Reference Book. 10. ed. Ashgate: Aldershot and Burlington, VT, 2005.

RAY, Joyce. The rise of digital curation and cyberinfrastructure:From experimentation to implementation and maybe integration. Library Hi Tech, v. 30, n. 4, p. 604-622, 2012.

RUUSALEPP, Raivo; DOBREVA, Milena. State of the art in digital preservation and multi-agent systems. INNOVATIVE DIGITAL PRESERVATION USING SOCIAL SEARCH IN AGENT ENVIRONMENTS, 2013. Disponível em: < http://durafile.eu/wpcontent/uploads/2014/08/D1-1_State-of-the-Art.pdf >. Acesso em: 19 jul. 2016.

RUSBRIDGE et al. The digital curation centre: a vision for digital curation. In: Local to Global Data Interoperability: challenges and technologies. 24-25 jun. Sardenha, Italia. [S.1.]: IEEE, 2005, p. 31-41. Disponivel em: <eprints.erpanet.org/82q01/DCC_Vision.pdf>. Acesso em: 12 jul. 2016.

SANTOS, Thayse Natália Cantanhede. Curadoria digital: o conceito no período de 2000 a 2013. 2014. 165 f., il. Dissertação (Mestrado em Ciência da Informação) - Universidade de Brasília, Brasília, 2014.

SAYÃO, Luis Fernando; SALES, Luana Farias. Curadoria digital: um novo patamar para preservação de dados digitais de pesquisa. Informação \& Sociedade: Estudos, v.22, n.3, p. 179191, set./dez. 2012. Disponível em:

<http://www.ies.ufpb.br/ojs/index.php/ies/article/view/12224/8586>. Acesso em: 23 fev. 2013. 
STATE LIBRARY OF NORTH CAROLINA. Digital Preservation Best Practices and Guidelines, 2013. Disponível em: <http://digitalpreservation.ncdcr.gov/>. Acesso em: 17 maio 2016.

UNIVERSITY OF MINNESOTA LIBRARIES. Digital preservation at the University of Minnesota Libraries: what is Digital Preservation? Disponível em: < https://www.lib.umn.edu/dp>. Acesso em: 05 jun. 2016.

URIBE-MARTÍNEZ, Luis; MACDONALD, Stuart. Un nuevo cometido para los bibliotecarios académicos: data curation. El profesional de la información, v. 17, n. 3, p. 273-280, 2008. Disponível em: <www.elprofesionaldelainformación.com/contenidos/2008/mayo/03.html>. Acesso em: 21 jul. 2016.

VIEIRA, Marcos Rodrigues. et. al. Bancos de dados no SQL: conceitos, ferramentas, linguagens e estudos de casos no contexto de Big Data. In: Simpósio Brasileiro de Bancos de Dados, 2012, Mato Grosso. Minicurso... Mato Grosso: Universidade Federal de Mato Grosso, 2012. Disponível em: <http://data.ime.usp.br/sbbd2012/artigos/pdfs/sbbd_min_01.pdf> Acesso em: 29 jul. 2016.

WEIDNER, Andrew James; ALEMNEH, Daniel Gelaw. Workflow Tools for Digital Curation. Code4Lib Journal., n. 20, 2013.

YAKEL, Elizabeth. Digital curation. OCLC Systems \& Services, v.23, n.4, 2007, p. 335340.
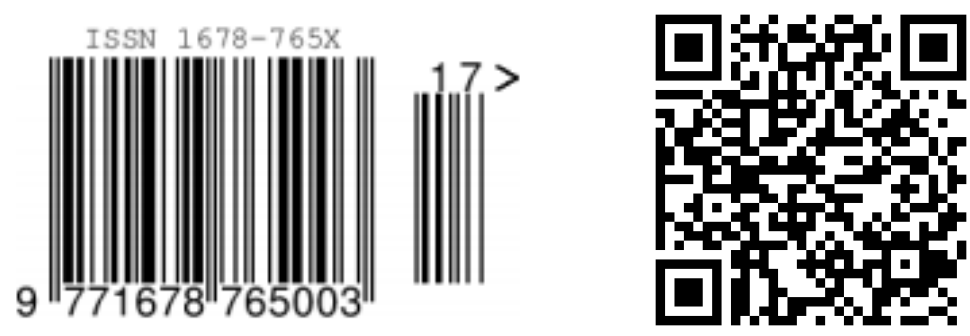